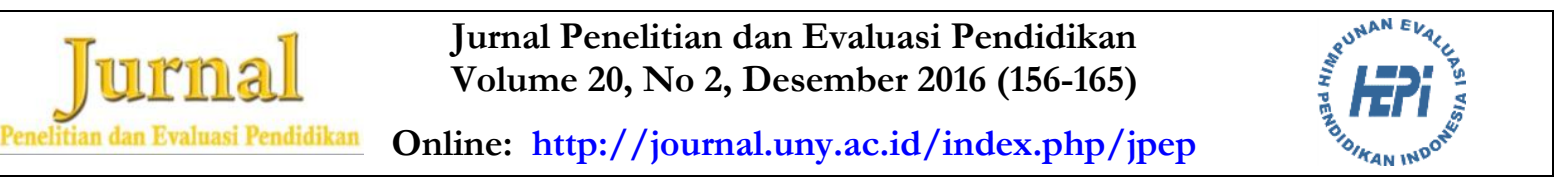

\title{
EFEKTIVITAS MODEL AMOVIE UNTUK MENINGKATKAN KEMAMPUAN TEACHERPRENEUR
}

\author{
Endang Mulyatiningsih \\ Pendidikan Tata Boga dan Busana Fakultas Teknik Universitas Negeri Yogyakarta \\ Jl. Colombo No. 1, Depok, Sleman 55281, Yogyakarta, Indonesia \\ Email: ememulya@gmail.com
}

\begin{abstract}
Abstrak
Penelitian ini bertujuan untuk: (1) mendeskripsikan efektivitas model AMOVIE dalam meningkatkan kemampuan teacherpreneur; (2) menganalisis dukungan penerapan model AMOVIE; dan (3) mengidentifikasi hambatan untuk menjadi teacherpreneur. Penelitian menggunakan metode deskriptif evaluatif. Populasi penelitian ini adalah seluruh peserta program kemitraan guru SMK dengan DUDI tahun 2014 dan 2015. Sampel ditetapkan menggunakan teknik simple random sampling pada 120 peserta program. Data diperoleh melalui kuesioner, observasi dan dokumentasi. Data dianalisis menggunakan statistik deskriptif kuantitatif dan kualitatif. Hasil penelitian menunjukkan: (1) penerapan model AMOVIE terbukti efektif dapat meningkatkan kemampuan teacherpreneur dari unsur karya inovatif pembelajaran; pengembangan diri, memperoleh penghasilan tambahan dari produksi barang dan jasa; (2) implementasi model AMOVIE mendapat dukungan izin, dana dan bimbingan selama OJT; dan (3) hambatan untuk menjadi teacherpreneur antara lain kurang motivasi pribadi (23,3\%); kurang menguasai IPTEK modern (30\%); kualitas (78,3\%) dan kuantitas (52,05\%) sarana dan prasarana untuk praktikum di SMK masih kurang dan beban kerja administrasi sekolah berlebihan (62,5\%).
\end{abstract}

Kata kunci: $A M T$, OJT, visual exbibition, teacherpreuneur

\section{EFFECTIVENESS OF AMOVIE MODEL FOR IMPROVING TEACHERPRENEUR CAPABILITY}

\begin{abstract}
The research aims to: (1) determine the effectiveness of the AMOVIE model in enhancing the teacherpreneur capability (2) analyze the support for AMOVIE model implementation; and (3) identify the obstacles to be teacherpreneur. This research used evaluative approach involving 120 participants of a partnership program between vocational teachers with industry. Data were obtained through questionnaires, observation and documentation. Data were analyzed using descriptive quantitative and qualitative techniqques. The results showed: (1) the implementation of the AMOVIE model was effective to improve the teacherpreneur ability in the aspects of inovative work of learning, continuing professional development (CPD), earning extra income from the production of goods and services; (2) the implementation of the AMOVIE model gets support for: permits, funding and guidance for OJT; and (3) the obstacles to be teacherpreneur are: lack of personal motivation (23.3\%); not mastering modern science and technology (30\%); quality $(78.3 \%)$ and quantity $(52.05 \%)$ insufficient facilities and infrastructure in vocational schools, and excessive workload of school administration $(62.5 \%)$.
\end{abstract}

Keywords: AMT, OJT, Visual exbibition, teacherpreuneur

Permalink/DOI: bttp://dx.doi.org/10.21831/pep.v20i2.7826 


\section{Pendahuluan}

AMOVIE (Achievment motivation training, On-the-job training, Visual exbibition dan Evaluation) merupakan model yang diterapkan pada program kemitraan guru produktif SMK dengan DUDI (Dunia Usaha dan Dunia Industri) yang diselenggarakan oleh Direktorat Pendidik dan Tenaga Kependidikan Pendidikan Menengah tahun 2014 - 2015. Program ini bertujuan untuk menyelaraskan kompetensi guru dengan kompetensi yang berkembang di DUDI. Hal ini dilakukan karena ilmu pengetahuan dan teknologi (IPTEK) di DUDI selalu berkembang lebih cepat daripada IPTEK yang dipelajari di SMK. Guru SMK perlu mengikuti perkembangan IPTEK di DUDI agar mampu menyiapkan lulusan yang kompetensinya relevan dengan kebutuhan DUDI.

Setelah program kemitraan guru SMK dengan DUDI berjalan beberapa tahun, keberhasilan program masih belum nampak dan tidak pernah diukur. Banyak peserta program yang hanya menjalankan kegiatan kemitraan tanpa hasil optimal. Agar hasil program kemitraan lebih efektif maka dirancang model AMOVIE. Implementasi model AMOVIE perlu dievaluasi supaya diketahui efektivitasnya dalam meningkatkan kompetensi keahlian dan kemampuan teacherpreneur.

AMT (Achievment motivation training) merupakan sebuah metode pelatihan yang banyak digunakan oleh satuan organisasi untuk memotivasi bawahannya agar mereka memiliki motivasi yang tinggi untuk berprestasi. Berdasarkan hasil studi Khomsatun (2013, p. 27) tindakan workshop achievement motivation training dan peer teaching efektif untuk meningkatkan kemampuan pengelolaan pembelajaran dan motivasi berprestasi para guru peserta MGMP Aqidah Akhlak MTs Kabupaten Boyolali. Dalam konteks penelitian ini, AMT diterapkan pada saat pembekalan program kemitraan guru SMK dengan DUDI untuk memotivasi peserta agar melaksanakan program dengan sebaik-baiknya untuk mencapai tujuan program yaitu meningkatkan kemampuan teacherpreneur.
Implementasi program kemitraan guru SMK dengan DUDI mengikuti pola pelatihan yaitu OJT (On-the Job Training). Menurut Dessler (2008, p. 273), On-the Job Training merupakan bentuk pelatihan dalam jabatan (ad hoc) yang dijadwalkan secara rutin dengan sistem pelatihan dan kunjungan (the training and visit. $T \& V$ ) yang disediakan oleh atasan langsung atau praktisi ahli untuk karyawannya. Pelatihan ini umumnya berorientasi pada teknologi yaitu untuk mencoba keterampilan dan pengetahuan baru yang sedang berkembang. Atasan langsung atau praktisi ahli dari setiap departemen ikut berperan dalam memberikan on-the-job training kepada staf saat melakukan aktivitas sehari-hari. Dalam model AMOVIE, peserta program kemitraan mengikuti OJT setelah mendapat pembekalan AMT. Materi yang dipelajari selama OJT dapat dikembangkan menjadi produk-produk teacherpreneur seperti modul, buku, media untuk meningkatkan kompetensi keahlian, memperbaiki kualitas pembelajaran dan pengembangan keprofesian berkelanjutan.

Hasil-hasil program kemitraan yang telah dilakukan melalui OJT kemudian dipamerkan (exbibition) pada saat diseminasi hasil program. Pameran adalah the act of presenting something to sight or view atau a collection of things (good or works of art etc.) for public display (www.thefreedictionary.com). Dalam terjemahan bebas, pameran adalah kegiatan untuk mempresentasikan sesuatu agar dapat dilihat atau display koleksi benda atau karya seni untuk masyarakat. Penyelenggaraan pameran sering dilakukan oleh pebisnis untuk penyebarluasan informasi dan promosi barang dan jasa. Hasil penelitian efektivitas pelaksanaan program pengembangan UKM yang dilakukan melalui kegiatan seminar, pengadaan modal, pelatihan untuk meningkatkan kualitas SDM UKM di bidang pemasaran dan penggunaan teknologi memperoleh informasi bahwa pameran atau promosi produk kemitraan antara UKM dengan Usaha Besar masih belum efektif karena masih banyak UKM yang tidak mau berubah dan merealisasikan pelatihan dan pengarahan yang mereka dapatkan (Lestari, 2011, p. 1). 
Dalam model AMOVIE ini, pameran merupakan kegiatan untuk men-display dan mempresentasikan hasil program kemitraan. Pameran bersifat kompetitif karena selama pameran dilakukan penilaian dan evaluasi oleh fasilitator untuk memilih perserta terbaik dari setiap kelompok program keahlian. Peserta terbaik diberi hadiah (reward) untuk memotivasi peserta program agar melaksanakan kegiatan dengan sebaik-baiknya. Melalui penilaian dan evaluasi ini diketahui efektivitas model AMOVIE dalam meningkatkan kemampuan teacherpreneur. Model AMOVIE secara visual diilustrasikan pada Gambar 1.

Efektivitas program dapat diukur dari ketercapaian tujuan. Program kemitraan guru SMK dengan DUDI menggunakan model AMOVIE dinyatakan efektif jika dapat mencapai tujuan program yaitu meningkatkan kemampuan teacherpreneur. Hal ini sejalan dengan definisi efektivitas menurut oxford dictionaries.com yaitu the degree to which something is successful in producing a desired result, Jika diterjemahkan, efektivitas adalah tingkat dimana program atau kegiatan telah sukses dapat mencapai hasil yang diinginkan. Jika setelah implementasi AMT dan OJT, peserta program tergugah semangatnya dan mau merintis jalan menjadi teacherpreneur maka model AMOVIE dinyatakan efektif.

Teacherpreneur adalah seorang guru yang memiliki jiwa wirausaha. Holden (2014, p.
11) menelaah hasil penelitian dan menemukan ciri-ciri wirausaha (entrepreneur) sukses yaitu memiliki berbagai atribut pribadi seperti cerdas, kreatif, pekerja keras, tekun, semangat, fleksibel, berjiwa pemimpin, dan percaya diri. Dalam telaahnya, Holden menyatakan bahwa entrepreneur adalah orang yang kreatif yaitu mampu mengembangkan produk atau jasa baru untuk melakukan bisnis. Orang kreatif memiliki kebutuhan untuk belajar terus-menerus, selalu ingin menemukan ide baru yang berbeda dari ide orang lain. Entrepreneur mampu bekerja keras untuk sukses, senang menyusun rencana yang padat (lebih dari 12 jam per hari) dan sering tidak memiliki waktu libur tetapi kesibukannya justru membuatnya bahagia.

Entrepreneur memiliki motivasi yang tinggi untuk sukses, mampu bangkit kembali setelah melewati masa sulit dan mampu bergerak cepat dalam menanggapi perubahan kebutuhan pasar. Entreprenuer mampu mengatur orang lain dan meyakinkan mereka untuk percaya pada visinya dalam rangka mencapai tujuan, Entrepreneur selalu menyusun perencanaan yang menyeluruh untuk mengurangi risiko sehingga mereka lebih percaya diri dalam mengambil keputusan. Entrepreneurship hanya dapat dilakukan oleh orang yang cerdas, ahli, dan memiliki pengalaman bisnis atau usaha.

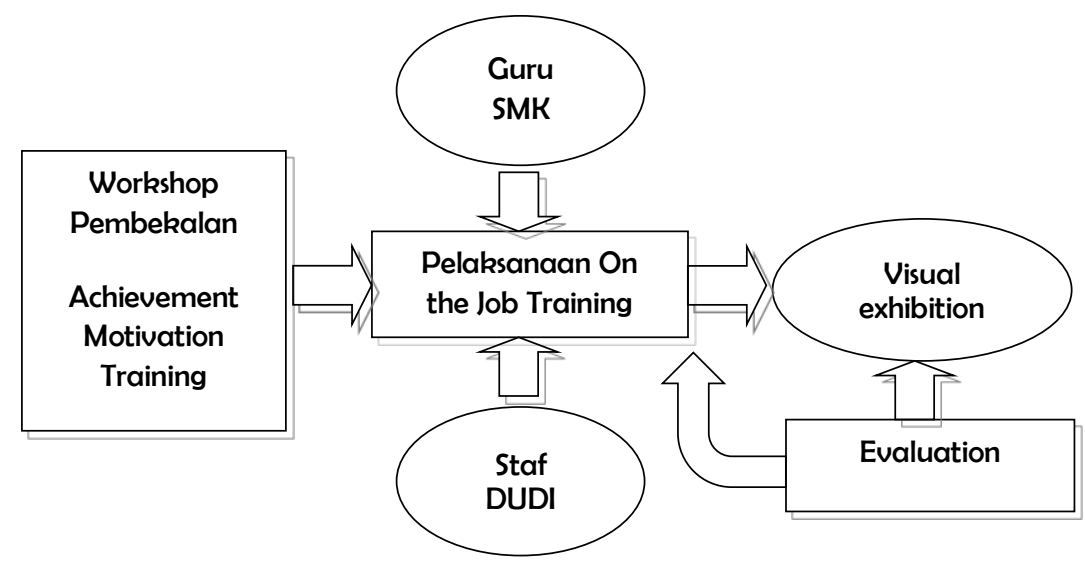

Gambar 1. Langkah-langkah Penerapan Model AMOVIE 
Davis (2009, pp.8-12) menganalogikan definisi entrepreneur dengan teacherpreneur sebagai berikut: an entrepreneur is "someone who organizes a business venture and assumes the risk for it." So, I define a teacherpreneur as "someone who organizes a classroom venture for learning and assumes the risk for it." Dalam terjemahan bebas entrepreneur adalah seseorang yang dapat mengorganisasikan sebuah bisnis dan berani menanggung resiko atas bisnis tersebut. Teacherpreneur adalah seseorang yang dapat mengorganisasikan kelas untuk belajar dan berani menanggung resiko atas kegiatan pembelajaran yang dilakukan. Definisi ini kurang tepat dianalogikan karena bisnis dan pembelajaran memiliki tingkat resiko yang berbeda. Resiko bisnis lebih kritis daripada resiko pembelajaran. Resiko bisnis dapat terjadi langsung setelah terjadi transaksi sedangkan resiko pembelajaran terjadi setelah pembelajaran berlangsung lama.

Teacherpreneurs merupakan pemimpin dalam komunitas dan sekolah di tempat kerjanya. Teacherpreneurs memiliki peran kompleks sebagai pakar pendidikan, konselor, advokat kebijakan, dan banyak lagi. Mereka adalah guru yang mengambil peran kepemimpinan tetapi tidak meninggalkan kelas untuk posisi administrasi. Teacherpreneur juga memiliki peran khusus di organisasi guru. Teacherpreneurs in this capacity teach half the week and use the other half of their time to advocate for education policy, collaborate with other teachers, and pursue other activities that advance the teaching profession. Teacherpreneur memiliki kapasitas menggunakan separoh waktunya untuk mengajar dan separoh lainnya untuk melakukan advokasi kebijakan pendidikan, berkolaborasi dengan guru lain, dan melakukan kegiatan lain yang dapat meningkatkan profesinya. Guru perlu diberi waktu dan kesempatan untuk menyiapkan pembelajaran yang terbaik dan tidak terlalu banyak dibebani dengan tugas mengajar atau tugas administrasi agar bisa menjadi teacherpreneur.

Menurut the Center for Teaching Quality (CTQ), teacherpreneurs adalah ahli kelas yang mencurahkan waktu untuk mengajar dan memimpin inovasi dalam praktik dan kebijakan. Northcentral University (2014, p.1) mengemukakan empat cara untuk menjadi teacherpreneur yaitu: teachers pay teachers, joint a teacherpreneur community; turn your teaching skills into a part time job; expand your teacherpreneur brand. Pertama, Teachers pay teachers yaitu sebagai pendidik profesional, guru harus tahu apa yang terbaik di kelas. "Guru Bayar Guru" adalah guru yang memiliki kemampuan untuk menjual keahlian khusus kepada guru lainnya dalam komunitas profesi guru Kedua, joint a teacherpreneur community; yaitu guru disarankan menemukan komunitas teacherpreneur di daerah agar dapat membangkitkan ide-ide baru dan belajar dari keberhasilan guru lain yang sudah berpengalaman. Ketiga, turn your teacbing skills into a part time job yaitu keterampilan memberi pelajaran kepada siswa yang mengalami kesulitan belajar misalnya: membuka les privat, menjadi tutor, atau pamong belajar. Keempat, expand your teacherpreneur brand yaitu guru yang telah dikenal orang banyak karena keahliannya atau memiliki brand (merk), dapat memperluas jaringan kerja melalui media blog agar ide-idenya lebih dikenal dan dimanfaatkan masyarakat luas.

Teacherpreneur adalah guru yang memiliki banyak tanggungjawab di dalam kelas, sekolah atau anggota masyarakat karena prestasinya berasal dari sana. Di dalam kelas, teacherpreneur adalah guru yang selalu mengembangkan pembelajaran inovatif dan efektif untuk mencapai learning outcome yang diharapkan. Guru menyiapkan peserta didik untuk dapat bersaing menghadapi dunia global, menghadapi perbedaan agama, ras dan budaya. Untuk kenaikan jabatan, teacherpreneur adalah guru yang dapat menulis artikel, membuat media, berpartisipasi di forum ilmiah, menjadi narasumber dalam seminar atau konferensi ilmiah. Sebagai anggota masyarakat, teacherpreneur adalah guru yang mau bergabung dengan guru lain dalam komunitas profesi guru, sharing inovasi untuk dapat memperbaiki kualitas mengajar.

Teacherpreneneur dapat diberi makna seorang guru atau pendidik yang memiliki komitmen tinggi terhadap pekerjaannya. Komitmen tersebut diwujudkan dengan melakukan pembelajaran yang berkualitas 
secara terus-menerus. Pelayanan jasa yang berkualitas berpengaruh terhadap kepuasan pelanggan dan berdampak pada kesetiaan pelanggan (Chakravarty, Feinberg, \& Rhee, 2004, pp.1-21). Pembelajaran adalah layanan jasa di bidang pendidikan. Pelanggan jasa layanan pendidikan adalah siswa, orang tua siswa dan masyarakat. Kepuasan pelanggan merupakan faktor kunci dalam membentuk keinginan pelanggan untuk membeli kembali jasanya di masa depan (Mittal \& Kamakura, 2001, pp.131-142). The satisfied customers will probably talk to others about their good experiences. Pelanggan yang merasa puas dapat berbicara dengan orang lain tentang pengalaman baik mereka (Jamal \& Naser, 2002, 146-160). Jika guru menerapkan prinsip-prinsip pembelajaran yang berkualitas, maka pelanggan akan merasa puas dan menggunakan kembali jasa pelayanannya. Pendidik yang telah memiliki kredibilitas baik, tidak perlu mencari peluang pekerjaan lagi untuk menambah penghasilan tetapi pekerjaanlah yang akan mencari dia dan antri menunggu untuk dilaksanakan.

Penelitian ini bertujuan untuk mendeskripsikan efektivitas model AMOVIE dalam meningkatkan kemampuan teacherpreneur dari aspek pembelajaran, pengembangan keprofesian secara berkelanjutan dan usaha menambah penghasilan. Selain itu, penelitian ini juga bertujuan mengidentifikasi dukungan yang diperoleh selama implementasi model AMOVIE dan hambatanhambatan yang dialami guru untuk menjadi teacherpreneur.

\section{Metode Penelitian}

Penelitian ini menggunakan metode penelitian deskriptif evaluatif. Populasi penelitian ini adalah peserta program "Pemerataan Mutu Keahlian Guru Produktif SMK melalui Kerjasama (kemitraan/partnership) dengan DUDI tahun 2014 dan tahun 2015" yang diselenggarakan oleh Direktorat Pembinaan Pendidik dan Tenaga Kependidikan (P2TK), Pendidikan Menengah (Dikmen). Populasi berjumlah 236 orang dan sampel diambil secara acak sederhana sebanyak 120 orang. Menurut (Borg \& Gall, 1989, p.176) sampel minimal untuk penelitian survei (deskriptif) adalah 100 orang per subkelompok mayor dan 20-50 orang untuk setiap sub kelompok minor.

Evaluasi dilaksanakan dengan langkah langkah penyusunan dan validasi instrumen penelitian, pengumpulan dan pengolahan data penelitian serta pelaporan hasil penelitian. Data dikumpulkan menggunakan kuesioner, lembar observasi, wawancara dan dokumentasi. Pengumpulan data dengan kuesioner dilakukan pada saat implementasi Acbievment Motivation Training. Kuesioner menggunakan bentuk jawaban terbuka dan skala Thrustone. Kuesioner dengan bentuk jawaban terbuka digunakan untuk mengidentifikasi hambatan guru untuk menjadi teacherpreneur. Kuesioner dengan skala jawaban Thrustone digunakan untuk mengumpulkan data kegiatan teacherpreneur yang telah dilakukan. Observasi digunakan selama dan sesudah guru melakukan on the job training (OJT). Lembar observasi diisi oleh instruktur DUDI dan kepala sekolah yang berfungsi untuk menilai kinerja peserta selama OJT. Dokumentasi digunakan pada saat kegiatan visual exhibition dengan merekam foto hasil kegiatan partnership antara guru SMK dengan DUDI.

Analisis data dilakukan secara deskriptif kuantitatif dan kualitatif. Data kuantitatif diperoleh dari kuesioner dan lembar observasi/dokumentasi penilaian dari instruktur DUDI dan kepala sekolah. Data kuantitatif dianalisis menggunakan persentase. Data kualitatif dari dokumentasi visual exbibition dilaporkan sesuai urutan tujuan penelitian.

\section{Hasil Penelitian dan Pembahasan}

Efektivitas Model AMOVIE dalam Meningkatkan Teacherpreneur

Efektivitas model dinilai dari ketercapaian tujuan program kemitraan guru produktif SMK dengan DUDI menggunakan model AMOVIE dalam meningkatkan kemampuan teacherpreneur. Kemampuan teacherpreneur dikelompokkan menjadi dua yaitu teacherpreneur yang berorientasi akademis dan 
ekonomis. Kegiatan guru SMK dalam teacherpreneur akademis meliputi peningkatan kompetensi keahlian, peningkatan kualitas pembelajaran dan lulusan dan pengembangan keprofesian berkelanjutan. Kegiatan guru SMK dalam teacherpreneur ekonomis meliputi produksi barang, pelayanan jasa dan perdagangan. Deskripsi data kegiatan teacherpreneur guru SMK peserta program kemitraan dilaporkan pada Gambar 2.

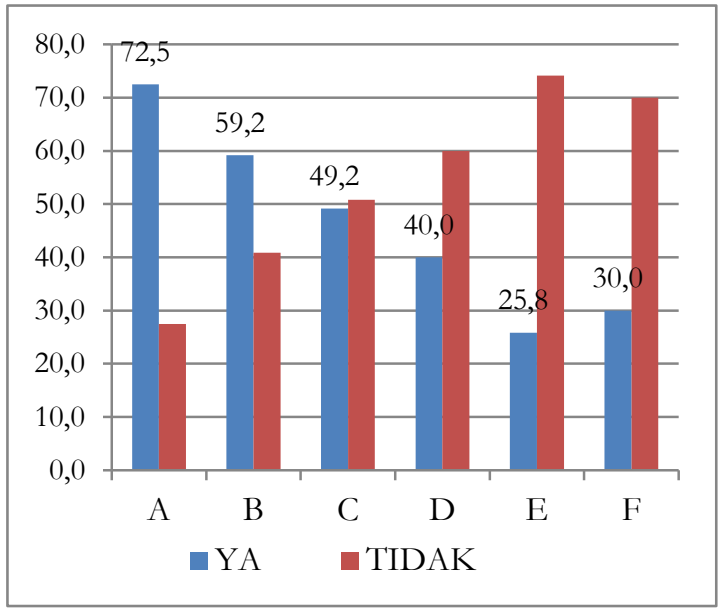

Gambar 2. Karya Inovasi Pembelajaran

Keterangan:

A. Karya teknologi tepat guna

B. Inovasi metode pembelajaran

C. Inovasi materi pembelajaran

D. Inovasi alat praktikum

E. Kreasi media pembelajaran

F. Penelitian tindakan kelas

Guru SMK lebih suka membuat karya nyata yang langsung dapat dimanfaatkan. Data menunjukkan karya teknologi tepat guna lebih banyak daripada karya ilmiah yang mendukung peningkatan profesionalisme berkelanjutan (PKB). Data menunjukkan guru SMK yang menulis penelitian dan media pembelajaran masih relatif sedikit. Hal ini disebabkan karena peserta lebih banyak berasal dari program studi keahlian Teknologi dan Rekayasa. Pertanian, dan Pariwisata.

Karya yang dihasilkan guru sangat banyak dan bervariasi sesuai dengan kompetensi keahlian guru SMK peserta program kemitraan. Berikut ini dilaporkan data kualitatif beberapa karya inovatif yang telah dibuat guru dari dokumentasi foto pameran (visual exhibition) dapat dilihat pada Gambar 3.
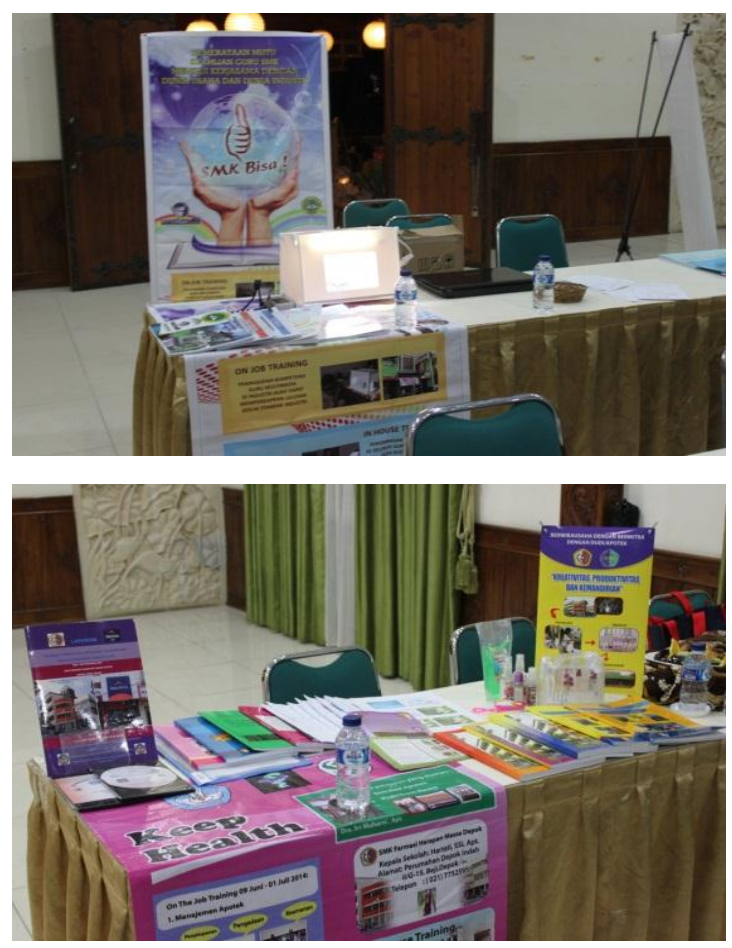

Gambar 3. Dokumentasi Visual Exhibition

Pada gambar 3 terlihat pameran guru produktif SMK dari program studi keahlian Teknik Audio Video dan SMK Farmasi. Guru SMK program keahlian Teknik Audio Video memamerkan karya studio mini yang digunakan untuk pemotretan benda-benda kecil seperti HP, jam tangan, perhiasan dan aksesoris. Hasil pemotretan digunakan untuk menjalankan e-commerce yang banyak dilakukan oleh peserta didik. Guru SMK program keahlian Farmasi memamerkan modul cetak dan produk farmasi berupa teh herbal, hand sanitary dan parfum untuk helm. Guru SMK program keahlian Desain dan Produksi Kria Tekstil membuat lenan rumah tangga dan benda-benda kerajinan menggunakan teknik quilting, Guru Teknologi Pengolahan Hasil Pertanian mengolah kelapa menjadi VCO (Virgin Coconut Oil) jenis MCFA (Medium Chan Fatty Acid) Karya inovasi guru produktif SMK masih banyak tetapi tidak mungkin dapat dilaporkan satu per satu.

Karya inovatif yang berorientasi pada peningkatan kualitas pembelajaran adalah

Efektivitas Model AMOVIE untuk Meningkatkan ... - 161

Endang Mulyatiningsih 
pembuatan media pembelajaran berbasis website, CD video pembelajaran interaktif, video training edutel, reservasi dan reception, media gambar bergerak, dan media plating masakan kontinental. Strategi pembelajaran inovatif yang diterapkan guru antara lain multi level model (MLM) yang dilakukan dengan cara satu anak yang pinter, membimbing dua anak lainnya. Bahan ajar yang ditulis oleh guru SMK peserta program kemitraan antara lain modul Pelayanan Makan dan Minum; Pengolahan Kentang dan Sayuran; Resep Masakan Standar. Hasil penelitian yang dapat diselesaikan guru antara lain perbedaan metakognitif siswa yang menggunakan metode think pair share dan problem solving.

Usaha yang telah dilakukan guru untuk mengembangkan keprofesian berkelanjutan (Continuing Professional Development) dapat dilihat pada Gambar 4. Berdasarkan Gambar 4 tersebut, guru telah berusaha mengembangkan diri melalui beberapa kegiatan. Jumlah kegiatan yang paling banyak diikuti adalah mengikuti pendidikan dan pelatihan (diklat) yang berkaitan dengan pendidikan ataupun kompetensi keahlian. Guru yang berminat melanjutkan studi masih relatif sedikit. Hal ini disebabkan karena guru memiliki kewajiban mengajar 24 jam per minggu sehingga mereka tidak memiliki waktu cukup untuk studi lanjut.

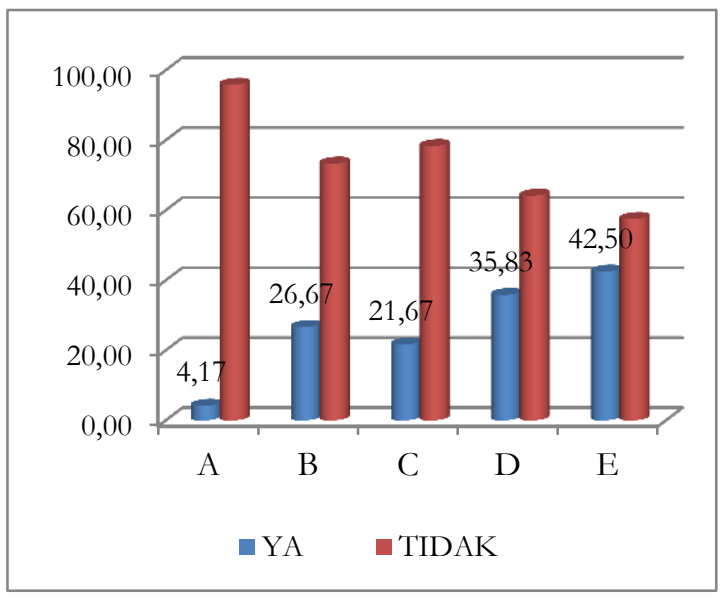

Gambar 4. Usaha Pengembangan Diri Guru SMK

A. Studi lanjut S2/S3

B. Diklat kompetensi bidang studi
C. Uji kompetensi keahlian

D. Diklat ilmu kependidikan

E. Diklat IPTEK baru

Guru memiliki beberapa kegiatan teacherpreneur sosial untuk meningkatkan prestasi belajar siswa antara lain: (1) memberi motivasi untuk berprestasi; membimbing siswa mengikuti lomba kompetensi siswa (LKS) dan membimbing siswa sampai menjadi entrepreneur, (2) mengatasi kesulitan belajar dengan membimbing siswa belajar di rumah; (3) membina karakter positif dengan cara membiasakan siswa disiplin pada saat pelajaran praktik, mengendalikan emosi siswa dengan musik dan memberi teladan karakter positif.

Teacherpreneur dilakukan guru untuk menambah penghasilan dan mendukung praktik kewirausahaan siswa. Pengalaman sukses mencari penghasilan tambahan dilakukan melalui produksi barang, jasa pelayanan dan bisnis perdagangan. Jenis produksi barang yang bernilai ekonomis dan relevan dengan bidang keahlian dapat dilaporkan pada Tabel 1.

Tabel 1. Teacherpreneur Ekonomis Bidang Produksi Barang

\begin{tabular}{llcc}
\hline \multirow{2}{*}{ No Jenis Usaha } & \multicolumn{2}{c}{ Jumlah } \\
& $\mathrm{n}$ & $\%$ \\
\hline 1 Usaha produksi di bidang & 13 & 10,8 \\
& pangan/boga \\
2 & $\begin{array}{l}\text { Membuat alat berteknolgi } \\
\quad \text { sederhana }\end{array}$ & 10 & 8,3 \\
3 & Membuat teralis besi untuk & 4 & 3,3 \\
$\quad$ rumah tangga & & \\
4 & Membuat benda kerajinan & 7 & 5,8 \\
5 & Pemanfaatan barang bekas & 4 & 3,3 \\
6 & Budidaya pertanian & 2 & 1,7 \\
7 & Mengelola dan memanfaatkan UP & 16 & 13,3 \\
8 & Tidak mengisi data & 64 & 53,3 \\
& Jumlah & 120 & 100 \\
\hline
\end{tabular}

Data pada Tabel 1 dan hasil wawancara menunjukkan teacherpreneur ekonomis yang dilakukan sangat bervariasi karena kompetensi keahlian peserta program kemitraan guru produktif SMK dengan DUDI juga bervariasi. Jenis usaha yang paling ba- 
nyak dikembangkan adalah usaha produksi pangan/boga seperti menerima pesanan makanan, kue, membuat minuman dalam kemasan, dsb. Jenis usaha yang dilakukan guru dalam bidang pelayanan dan jasa intelektual dilaporkan pada Tabel 2.

Tabel 2. Teacherpreneur Ekonomis bidang Jasa Intelektusl

\begin{tabular}{llcc}
\hline \multirow{2}{*}{ No Jasa Intelektual } & \multicolumn{2}{c}{ Jumlah } \\
& & $\mathrm{n}$ & $\%$ \\
\hline 1 & Instruktur pelatihan, tutor & 13 & 10,8 \\
2 & Teknisi/jasa perbaikan alat & 33 & 27,5 \\
3 & Fotografi dan video shooting & 4 & 3,3 \\
4 & Tidak ada data & 70 & 58,3 \\
& Total & 120 & 100 \\
\hline
\end{tabular}

Untuk menambah penghasilan, guru SMK melakukan kegiatan pelayanan jasa intelektual yaitu menjadi instruktur pelatihan dan tutor bimbingan belajar. Guru yang memiliki keahlian teknik membuka jasa perbaikan alat-alat teknik seperti bengkel mobil, motor, dinamo, servis HP dan instalasi listrik, dan sebagainya. Guru program keahlian multi-media mengembangkan jasa video shooting.

Dukungan Implementasi Model AMOVIE

Tabel 3. Dukungan Implementasi Model AMOVIE dalam Meningkatkan Kemampuan Teacgerpreneur.

\begin{tabular}{lcccc}
\hline Jenis dukungan & \multicolumn{2}{c}{ Ya } & \multicolumn{2}{c}{ Tidak } \\
SMK & $\mathrm{f}$ & $\%$ & $\mathrm{f}$ & $\%$ \\
\hline Memberikan ijin mengikuti & 120 & 100 & 0 & 0,0 \\
OJT & & & & \\
$\begin{array}{l}\text { Memberi dana tambahan } \\
\text { Memfasilitasi kegiatan IHT }\end{array}$ & 120 & 100 & 0 & 0,0 \\
$\begin{array}{l}\text { di sekolah. } \\
\begin{array}{l}\text { Mendukung pengembangan } \\
\text { teacherpreneur }\end{array}\end{array}$ & 77 & 64,2 & 43 & 35,8 \\
\hline DUDI & $\mathrm{f}$ & $\%$ & $\mathrm{f}$ & $\%$ \\
\hline $\begin{array}{l}\text { Membimbing guru belajar } \\
\text { keterampilan }\end{array}$ & 120 & 100 & 0 & 0,0 \\
$\begin{array}{l}\text { Memberi materi/ modul } \\
\text { untuk belajar }\end{array}$ & 104 & 86,7 & 16 & 13,3 \\
$\begin{array}{l}\text { Memberi media untuk } \\
\text { mengajar }\end{array}$ & 96 & 80,0 & 24 & 20,0 \\
\hline
\end{tabular}

Selama pelaksanaan program kemitraan menggunakan model AMOVIE, guru memperoleh dukungan dari SMK dan DUDI seperti tertera pada Tabel 3 .

Semua SMK mendukung gurunya untuk mengikuti OJT (on the job training) di DUDI. SMK yang sudah maju berani memberi dukungan dana tambahan, bahkan tanpa program kemitraan pun mereka telah mengirimkan guru untuk melaksanakan OJT di DUDI secara bergantian. SMK yang sudah maju dapat membiayai kegiatan OJT dari unit produksi yang dimiliki.

Hambatan menjadi Teacherpreneur

Hambatan yang dihadapi guru untuk menjadi teacherpreneur berasal dari faktor internal dan eksternal. Berdasarkan hasil identifikasi, hambatan untuk menjadi teacherpreneur antara lain disebabkan oleh beberapa alasan yang dilaporkan pada Tabel 4 .

Hambatan guru dari faktor internal antara lain motivasi pribadi yang kurang $(23,3 \%)$, tidak dapat mengelola waktu dengan baik $(37,5 \%)$, dan kurang menguasai IPTEK modern (30\%). Hambatan eksternal yang dialami guru antara lain adalah kualitas $(78,3 \%)$ dan kuantitas $(52,05 \%)$ sarana dan prasarana fisik untuk praktikum kurang dan selalu tertinggal dengan kualitas yang dimiliki oleh DUDI. Hambatan nonfisik yang berasal dari sekolah dapat diidentifikasi berupa beban kerja administrasi berlebihan $(62,5 \%)$ dan kesempatan mengikuti diklat kurang $(45,83)$. Guru terpaksa sering meninggalkan tugas mengajar di kelas karena ada tugas tambahan dan menghadiri undangan dari beberapa stakeholder. Tugastugas administrasi pembelajaran seperti menyusun persiapan mengajar dan penilaian hasil belajar terlalu banyak sehingga guru kurang waktu untuk pengembangan diri.

Hasil wawancara dengan beberapa guru yang enggan menulis karya ilmiah (penelitian) diperoleh informasi sebagai berikut: (1) tidak ada pemberi dana penelitian seperti dosen; (2) hasil penelitian sering tidak diakui untuk kenaikan pangkat; (3) kemampuan dan kemauan menulis kurang mendukung; (4) budaya menulis ilmiah di sekolah kurang mendukung.

Efektivitas Model AMOVIE untuk Meningkatkan ... 163 
Tabel 4. Hambatan Internal menjadi Teacherpreneur

\begin{tabular}{lccccc}
\hline & \multicolumn{3}{c}{ YA } & \multicolumn{3}{c}{ TIDAK } & Total \\
& Jumlah & $\%$ & Jumlah & $\%$ & \\
\hline Motivasi pribadi yang kurang & 28 & 23,33 & 92 & 76,67 & 120 \\
Kurang konsentrasi kerja & 32 & 26,67 & 88 & 73,33 & 120 \\
Tidak mampu mengelola waktu dengan baik & 45 & 37,50 & 75 & 62,50 & 120 \\
Kurang kreatif merancang desain produk & 25 & 20,83 & 95 & 79,17 & 120 \\
Kurang terampil dan menguasai materi & 29 & 24,17 & 91 & 75,83 & 120 \\
Kurang menguasai perkembangan IT & 24 & 20,00 & 96 & 80,00 & 120 \\
Kurang menguasai IPTEK modern & 36 & 30,00 & 84 & 70,00 & 120 \\
Kurang pengalaman mendidik & 24 & 20,00 & 96 & 80,00 & 120 \\
Kurang pengalaman mengatasi masalah pribadi & 23 & 19,17 & 97 & 80,83 & 120 \\
Kurang pengalaman mengoperasikan alat berteknologi tinggi & 27 & 22,50 & 93 & 77,50 & 120 \\
Kecemburuan kepada guru lain yang sukses & 16 & 13,33 & 104 & 86,67 & 120 \\
Banyak guru yang kurang disiplin & 31 & 25,83 & 89 & 74,17 & 120 \\
Dukungan kepala sekolah kurang & 15 & 12,50 & 105 & 87,50 & 120 \\
Beban kerja yang berlebihan & 88 & 73,33 & 32 & 26,67 & 120 \\
Kesempatan mengikuti diklat kurang & 55 & 45,83 & 65 & 54,17 & 120 \\
Jumlah siswa terlalu banyak & 36 & 30,00 & 84 & 70,00 & 120 \\
Sarana dan prasana pembelajaran kurang & 51 & 42,50 & 69 & 57,50 & 120 \\
Sarana dan prasana bengkel terbatas & 63 & 52,50 & 57 & 47,50 & 120 \\
Jumlah peralatan praktikum kurang & 71 & 59,17 & 49 & 40,83 & 120 \\
Kualitas peralatan praktikum kurang & 94 & 78,33 & 26 & 21,67 & 120 \\
Bahan praktik kurang dan sulit diperoleh & 47 & 39,17 & 73 & 60,83 & 120 \\
Tidak tersedia koneksi jaringan & 21 & 17,50 & 99 & 82,50 & 120 \\
Tugas tambahan nonKBM dari sekolah terlalu banyak & 71 & 59,17 & 49 & 40,83 & 120 \\
Beban administrasi guru dari sekolah sangat berlebihan & 75 & 62,50 & 45 & 37,50 & 120 \\
Sering mendapat undangan-undangan & 38 & 31,67 & 82 & 68,33 & 120 \\
Tenaga pengajar masih kurang & 42 & 35,00 & 78 & 65,00 & 120 \\
Kebijakan yang mendukung siswa bekerja keras masih lemah & 34 & 28,33 & 86 & 71,67 & 120 \\
Penegakan kedisiplinan di sekolah masih lemah & 36 & 30,00 & 84 & 70,00 & 120 \\
Peraturan sekolah kurang bersinergi dengan guru & 11 & 9,17 & 109 & 90,83 & 120 \\
Kerjasama antar warga sekolah yang kurang solid, & 12 & 10,00 & 108 & 90,00 & 120 \\
\hline & & & & &
\end{tabular}

\section{Simpulan}

Setelah menggunakan model AMOVIE, peserta program kemitraan guru SMK dengan DUDI mampu menunjukkan kemampuan teacherpreneur. Hasil yang ditunjukkan pada saat pameran berupa karya inovatif pendukung peningkatan kompetensi keahlian, peningkatan kualitas pembelajaran/lulusan, pengembangan keprofesian berkelanjutan, dan penambah penghasilan.
Dukungan yang diperoleh selama implementasi model AMOVIE pada program partnership guru produktif SMK dengan DUDI berasal dari SMK dan DUDI. Dukungan dari SMK berupa izin untuk mengikuti kegiatan, bantuan dana, dan fasilitasi penerapan hasil OJT (kemitraan) di SMK. Dukungan dari DUDI berupa fasilitasi kegiatan selama pelaksanaan OJT, dan pemberian materi berupa modul dan media yang dapat diterapkan di SMK. 
Hambatan yang dialami untuk menjadi teacherpreneur berasal dari faktor internal guru dan eketernal SMK. Hambatan internal berupa motivasi berprestasi dan kompetensi IPTEK terbaru masih perlu ditingkatkan. Hambatan eksternal berasal dari sarana fisik dan nonfisik SMK. Hambatan sarana fisik sebagian besar berasal dari peralatan bengkel/laboratorium yang masih kurang kuantitas ataupun kualitasnya. Hambatan nonfisik berasal dari beban tugas administrasi sekolah berlebihan sehingga guru tidak memiliki waktu untuk mengembangkan diri.

Berdasarkan hasil penelitian ini disarankan kepada: (1) perancang program pembinaan guru agar menggunakan pendekatan motivation training dan exbibition untuk meningkatkan keefektifan hasil programnya; (2) sekolah dan pengambil kebijakan agar tidak terlalu banyak memberikan tugas administrasi kepada guru supaya mereka lebih produktif dalam pengembangan profesi dan meningkatkan kualitas pembelajaran; (3) sekolah sebaiknya menfasilitasi guru untuk mengembangkan media dan perangkat pembelajaran untuk meningkatkan kualitas proses pembelajaran.

\section{Daftar Pustaka}

Borg, W. R., \& Gall, M. D. (1989). Educational research: an introduction (4th ed.). New York: Longman.

Chakravarty, S., Feinberg, R., \& Rhee, E.-Y. (2004). Relationships and individuals' bank switching behavior. Journal of Economic Psychology, 25(4).

Davis, V. (2009). Influencing positive change: the vital behaviors to turn schools toward success. Teacher Librarian, 37(2). Retrieved from https://www.learntechlib.org/p/7057 8

Dessler, G. (2008). Human resource management (11th ed.). Upper Saddle
River, NJ: Pearson Prentice Hall.

Holden, J. (2014). Principles of entrepreneurship.

The U.S. Department of State's

Bureau of International Information

Programs. Retrieved from

http://beijing.usembassy-

china.org.cn/uploads

Jamal, A., \& Naser, K. (2002). Customer satisfaction and retail banking: an assessment of some of the key antecedents of customer satisfaction in retail banking. International Journal of Bank Marketing, 20(4), 146-160. https://doi.org/10.1108/02652320210 432936

Khomsatun, S. (2013). Efektivitas workshop achievment motivation training (AMT) dan peer teaching terhadap peningkatan kompetensi engelolaan pembelajaran. Sekolah Tinggi Agama Islam Salatiga. Retrieved from http://perpus.iainsalatiga.ac.id/docfile s/fulltext/f7df957e1c328499.pdf

Lestari, D. S. (2011). Efektivitas pelaksanaan program pengembangan UKM (studi dada dinas koperasi kota medan). Retrieved January 6, 2016, from

http://repository.usu.ac.id/handle/12 $3456789 / 29811$

Mittal, V., \& Kamakura, W. A. (2001). Satisfaction, repurchase intent, and repurchase behavior: investigating the moderating effect of customer characteristics. Journal of Marketing Research, 38(1).

Northcentral University. (10 Maret 2014). 4 Tips on How to Become Teacherpreneur. Retrieved Decemember 27, 2015, from http://www.ncu.edu/blog 